\title{
The application of the optical system ATOS II for rapid prototyping methods of non-classical models of cogbelt pulleys
}

\author{
Piotr Krawiec ${ }^{1, *}$, Grzegorz Domek ${ }^{2}$, tukasz Warguła ${ }^{1}$, Konrad Waluś ${ }^{1}$, Jarosław Adamiec ${ }^{1}$ \\ ${ }^{1}$ Poznań University of Technology, Katedra PKM, Piotrowo 3 60-965 Poznań, Poland \\ ${ }^{2}$ Kazimierz Wielki Uniwersity, Chodkiewicza 30, 85-064 Bydgoszcz, Poland
}

\begin{abstract}
The widespread application of both gear wheels and cogbelt pulleys with noncircular generating line in technique stimulates the development of manufacturing and measuring methods of these wheels. The paper presents the rapid prototyping methods of models of cogbelt pulleys with nocircular evelope. Evaluation method of manufacturing accuracy of cogbelt pulleys, which are applied in unevenrunning belt transmissions, are presented. These transmissions are widely applied in steering techniques and drives of machines and devices. Verification of mapping accuracy of shape of geometrical model of cogbelt pulley was done with the application of noncontact optical system i.e. coordinate optical scanner GOM Atos Compact Scan 5M GOM company.
\end{abstract}

Keywords: cogbelt pulleys, belt transmissions, ATOS Compact Scan

\section{Introduction}

One of the key factors of economic growth of enterprises is inter alia ensuring proper quality and competitiveness of produced goods. Competitiveness may be defined as the ability of panning, creating and selling a product which is more attractive than other products available on the market. It is vital to launch new products quickly and at the same time take into account individual needs of future customers.

In order to comply with these conditions it is necessary to use modern modelling tools, computer simulations and prototyping. One of the new methods of increasing the competitiveness of companies that deal with machines and devices production is using the designing and manufacturing technique called Rapid Prototyping RP.

This notion refers to all techniques of allow for rapid manufacturing physical models of parts and units. The task of Rapid Prototyping techniques is to obtain a full-value product with the same durability, visual and aesthetic features as can be obtained using traditional manufacturing methods. Modern process of designing and manufacturing should be restricted to feedback loop in a form of geometric accuracy analysis of a prototype using a control - measurement method named Rapid Inspection - RI (Fig. 1). This method means a quick checking of parameters' compliances of the product with the use of a chosen RP

\footnotetext{
*Corresponding author: piotr.krawiec@put.poznan.pl
}

Reviewers: Andrej Czán, Milan Sága 
technique (mainly its shape and surface) and comparing it with a corresponding CAD model or standard.

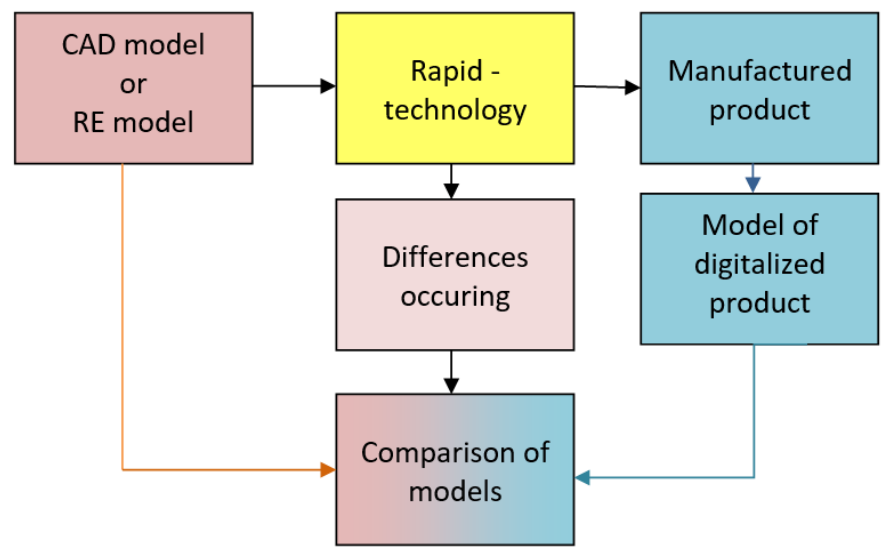

Fig. 1. The principle of Rapid Inspection process [1]

The Rapid Prototyping techniques were used to create an example of construction solution such as uneven-running strand transmissions [2] or cog belt transmissions with periodically variable transmission ratios [3]. Such transmissions allow to obtain periodically variable kinematic characteristics during one cycle of transmission by using elliptical cogbelts or pulleys (Fig. 2).

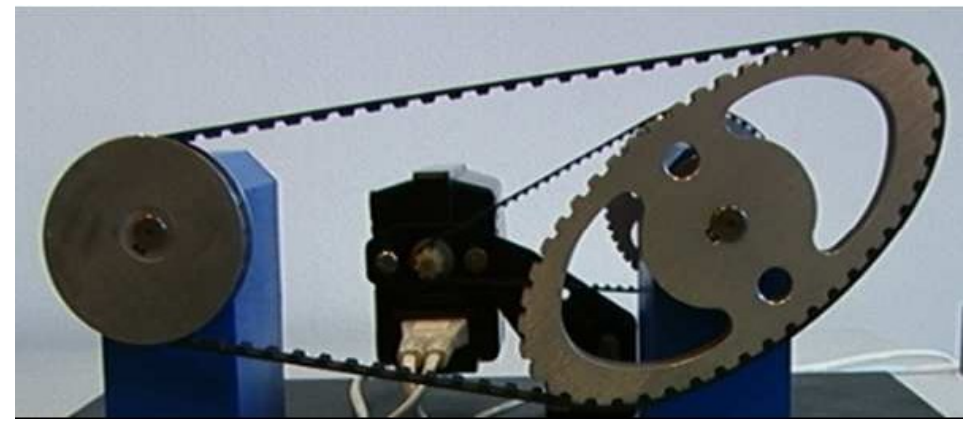

Fig. 2. Two-wheeled uneven-running strand transmission with a cog belt

The issues concerning the geometric characteristics of such transmissions are accessible in papers $[3,4]$, whereas the detailed description of possible manufacturing methods was characterised and exemplified in papers [5-7].

\section{The proposed method of manufacturing the pulleys of uneven- running strand transmission}

In search for precise and cheap methods of manufacturing elliptical pulleys the following universal technological machines were used: CNC milling machines, wire cutters, water jet cutters etc., or advanced systems like CAD and CAD/CAM. Also attention was paid to the need of using standard tools and ensuring the manufacturing precision in the area of geometric and stereometric characteristics of the surfaces. The method that allows fulfilling these requirements in case of elliptical pulleys is teeth processing with the use of CNC milling machine. Using standard and universal technological machines as well as classic tools is connected with simplifying the technological process as well as low production 
costs. In order to conduct this process it was necessary to prepare a software to steer the work of devices/tools. It was made with the use of commonly known ISO code and parts geometry in CAD system. In the case described here a 2D model was made in AutoCAD system which allows for designing conic sections and B-spline. This programme makes it is first to appoint and then exemplify with the use of any word processor the data necessary to create a software of processing the outline being shaped. The vital advantage of a universal CNC milling machine is the possibility of simulating the process (Fig. 3) directly from the level of steering panel. It enables to verify ( without any mistakes) the steering programs and allows to detect possible interferences in the configuration: the processed object - machine tool - tool before starting the shaper.

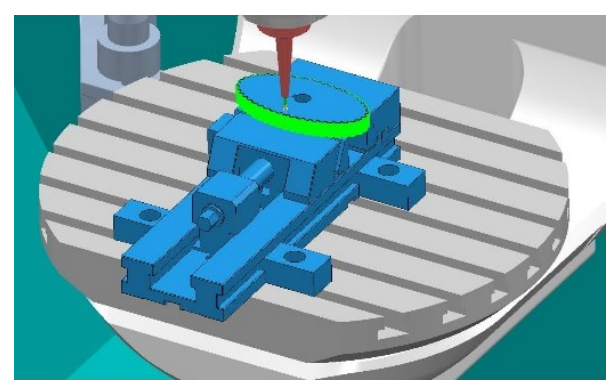

Fig. 3. The simulation of shaping the elliptical pulley

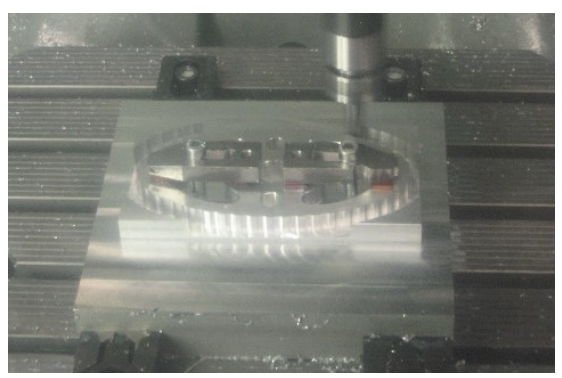

Fig. 4. Shaping the elliptical pulley with flutes

On the basis of preliminary analysis of construction documentation of the pulleys it could be stated that is necessary to involve three technological steps. The first of them was to remove excessive material from the rectangular- shaped semi-finished product with the use of flute milling cutter of $\varnothing 6 \mathrm{~mm}$ (Fig. 4). In the second step the finishing milling cutter of $\varnothing 4 \mathrm{~mm}$ was used and the final shape of teeth was obtained with the use of cutter of $\varnothing 2$ $\mathrm{mm}$. The shaping effect of exemplary elliptical pulleys is shown in Figure 5.

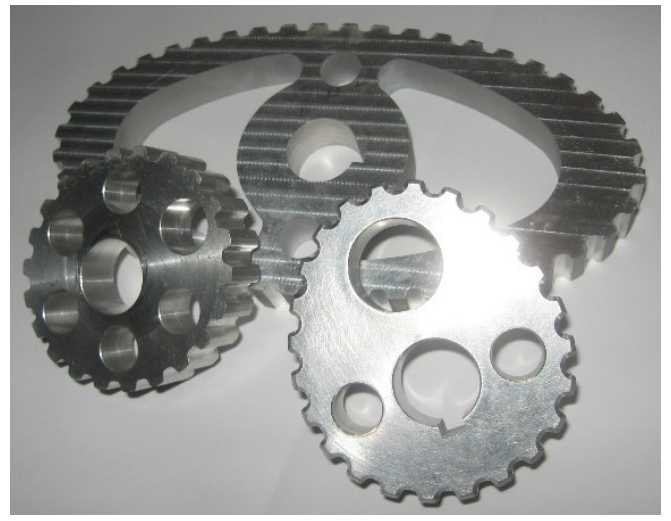

Fig. 5. The exemplary elliptical pulleys made with the use of universal CNC milling machine

\section{The proposal of the measurement methods of geometrical characteristics of nonstandard pulleys}

The authors of this article have not so far come across literature that would inform about the methods or measuring procedures of nonstandard pulleys. One of the possible options to be chosen is identification and verification of accuracy of geometry projection of such 
pulleys using noncontact measurement methods. The noncontact measurement methods of 3D models geometry are: handheld laser scanning, laser scanning with head installed on CMMs, optical scanning, computer tomography. Laser scanning enables to measure objects with very complex shapes. The measurement may be done in two ways. The first one is connected with using scanning heads fixed directly on CMM or cantilever arm. The second one is based on using a self-positioning handheld laser scanning. These devices allow in the digitalisation process to convert geometrical objects into 3D digital form. The working principle of self-positioning handheld laser scanning is usually connected with two combined processes: laser triangulation and marker detection. Triangulation means measuring an object in two perpendicular directions in coordinate system. The data obtained from triangular measurements are linked into one object with the use of markers detection (Fig. 6)

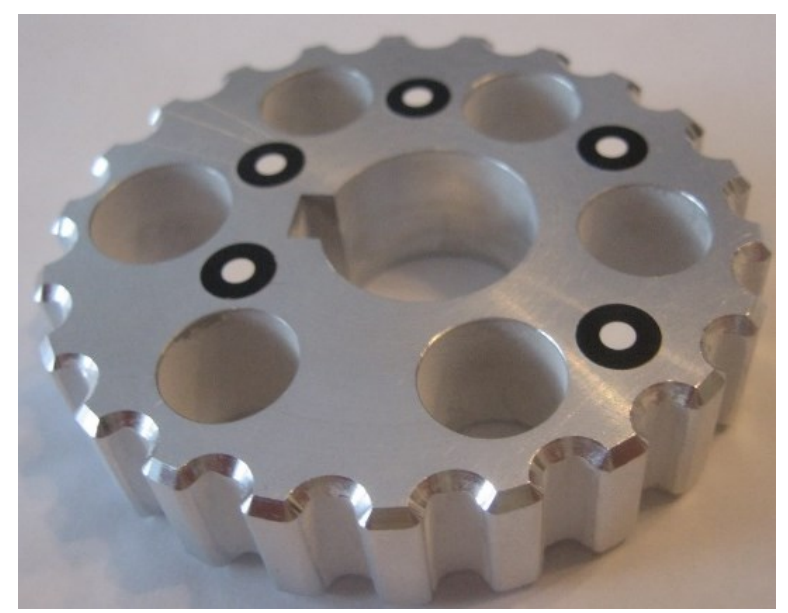

Fig. 6. Cogbelt pulley with marked reference points (markers)

Markers should firstly be placed, irregularly, onto the model or special mat that enables the scanner to recognize its position against the object. Handheld scanner during the measurement is moved freely by the operator around the measured object. The great advantage of such solution is the randomness of relative position of scanner and the object; it also eliminates the necessity of preparing a few point clouds from different positioning of the scanner and later linking them. Optical noncontact laser enables the measurement and to capture accurately the geometry of complex-shaped objects. The basis for scanning process is the analysis of line diffractions in a series of lined images projected on the object. When the surface is flat, the lines are parallel. If the surface of the object is curvilinear then the lines are diffracted in accordance with the shape. The diffraction is registered by a camera, processed by algorithms that take into account the parameters of optical system. The obtained set of points of $\mathrm{x}$, y coordinates is a computer mapping of the surface of a scanned object. The software of scanning systems allows to: combine the scanned images in order to obtain the whole measured surface, remove the measurement inaccuracy, compete the missing parts of the surface and prepare a ready CAD model. The accuracy of results obtained in his way of measurement depends on the kind of probe head used and the measurement area of the surface of the object being measured as well as kind of ray emitted. 


\section{The measurements of geometrical characteristics of pulleys}

The analysis of accuracy of mapping the geometrical shape of manufactured cogbelt pulleys was conducted with the use of noncontact optical system based on coordinate optical scanner GOM Atos Compact Scan 5M (Fig. 7). In order to conduct the measurement the measurement area SO 125 was used with the measurement range of $25 \times 90 \times 90 \mathrm{~mm}$. The scanning accuracy for this measurement area is at the level of 0.010 $\mathrm{mm}$.

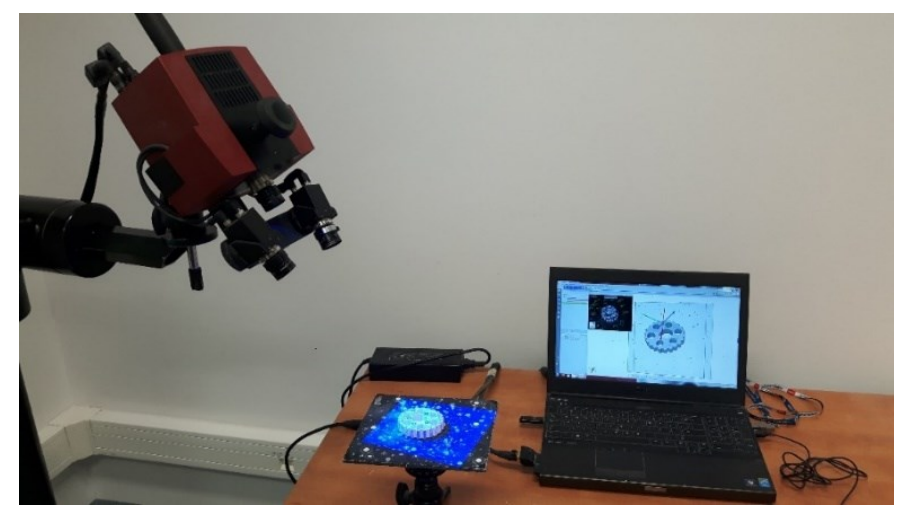

Fig . 7. The measurement of geometric characteristic of cogbelt pulleys with the use of ATOS II system

Before Canning the pulley to be measured was covered with a thin layer of chalk to obtain a matt surface. After scanning the model was put on CAD model with the use of Best fit method. The measurement analysis was made with the use of software GOM Inspect Professional V7 SR2. The exemplary measurement results are shown in Figs. 8-10.

The inaccuracy on the edges of the pulley (dark blue colour) is a result of an inaccurate deflection of the pulley edge in reference to CAD model. The same refers to the inaccuracies of holes lowering the weight of pulley. These inaccuracies are irrelevant for the proper functioning of the transmission.

\section{Summary}

The analysis of accuracy of mapping the geometrical shape of cogbelt pulleys with the use of optic scanning system ATOS II may be applied at all stages of the technological process of the production. The advantage of noncontact method is that the measurements may be carried out quickly and the results obtained and their analyses do not differ from the accuracy of contact measurements.

The analysis of accuracy of manufacturing the cogbelt pulleys may be visualized with the use of software GOM Inspect V7 SR2 showing the detailed deflections of dimensions specified in chosen points of pulley's surface and specified profiles of rim sections. As the detailed report is very vast, this article presents only some chosen figures. On the basis of the comparison of the researched pulleys with 3D-CAD models designed in software AutoCAD and Inventor it can be stated that there are visible divergences of dimensions within the range from $-0,019$ to $+0,014 \mathrm{~mm}$. The divergences occuring in the dimensions of the upper edge of the hub and teeth of the nominal model and the researched pulleys may result from the inaccurate mechanical working, but its value does not exclude this universal manufacturing method to be used for a mass production of pulleys. 

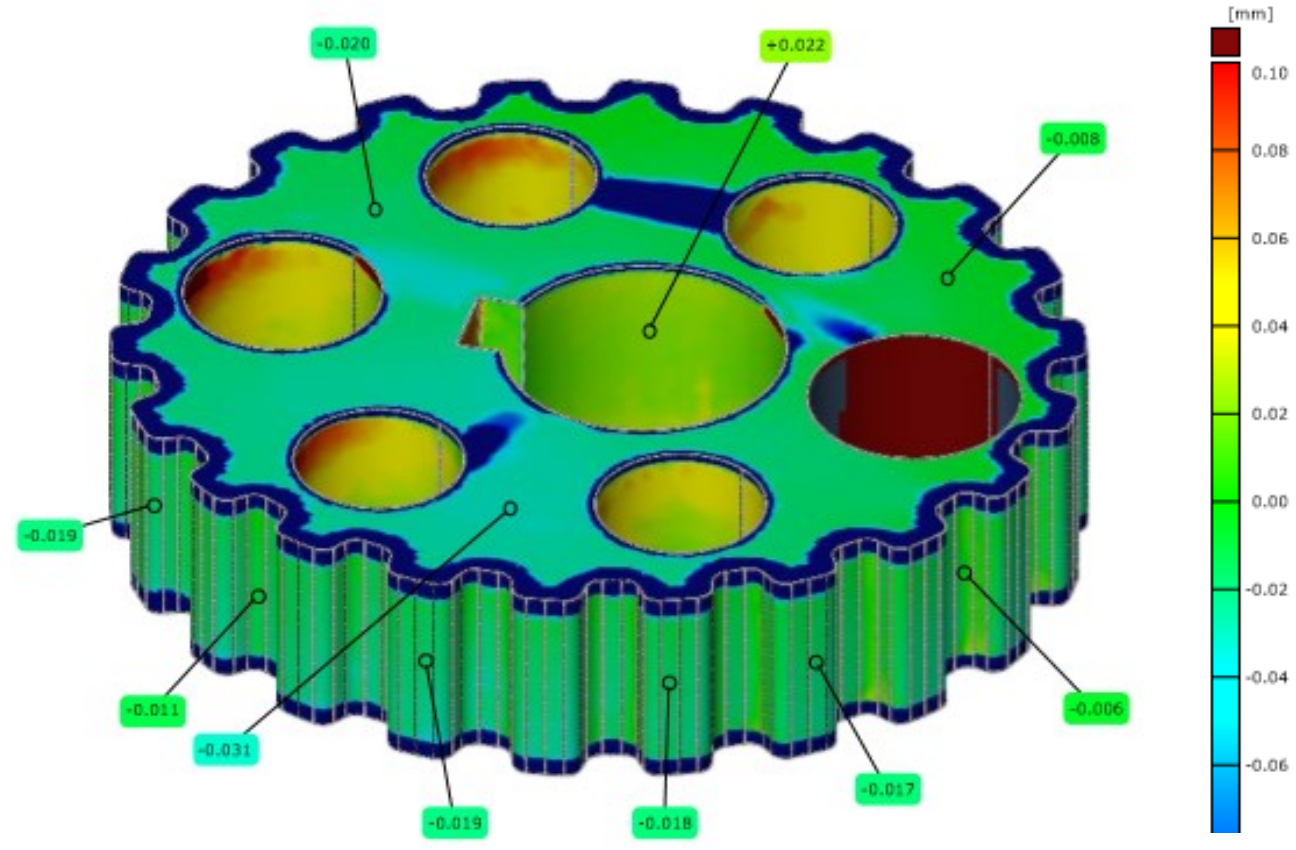

Fig. 8. The accuracy of mapping of geometrical shape of the cogbelt pulley
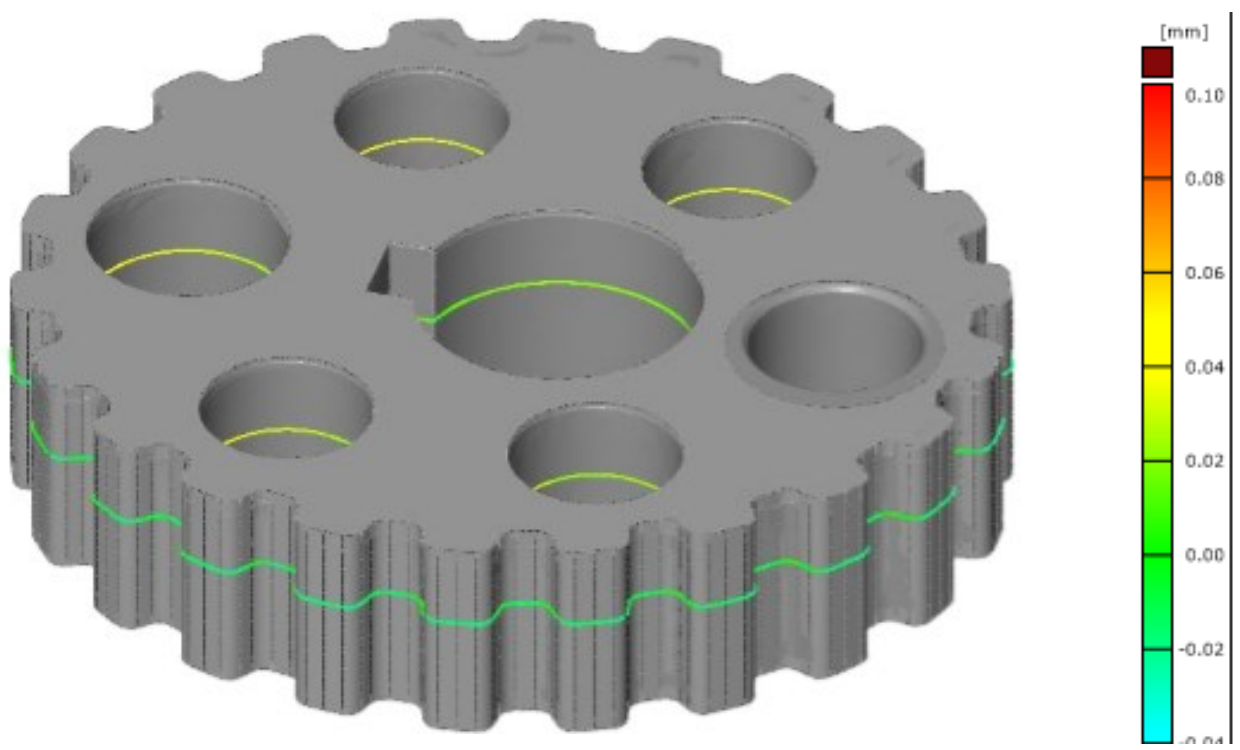

Fig. 9. The examplary section of a pulley 

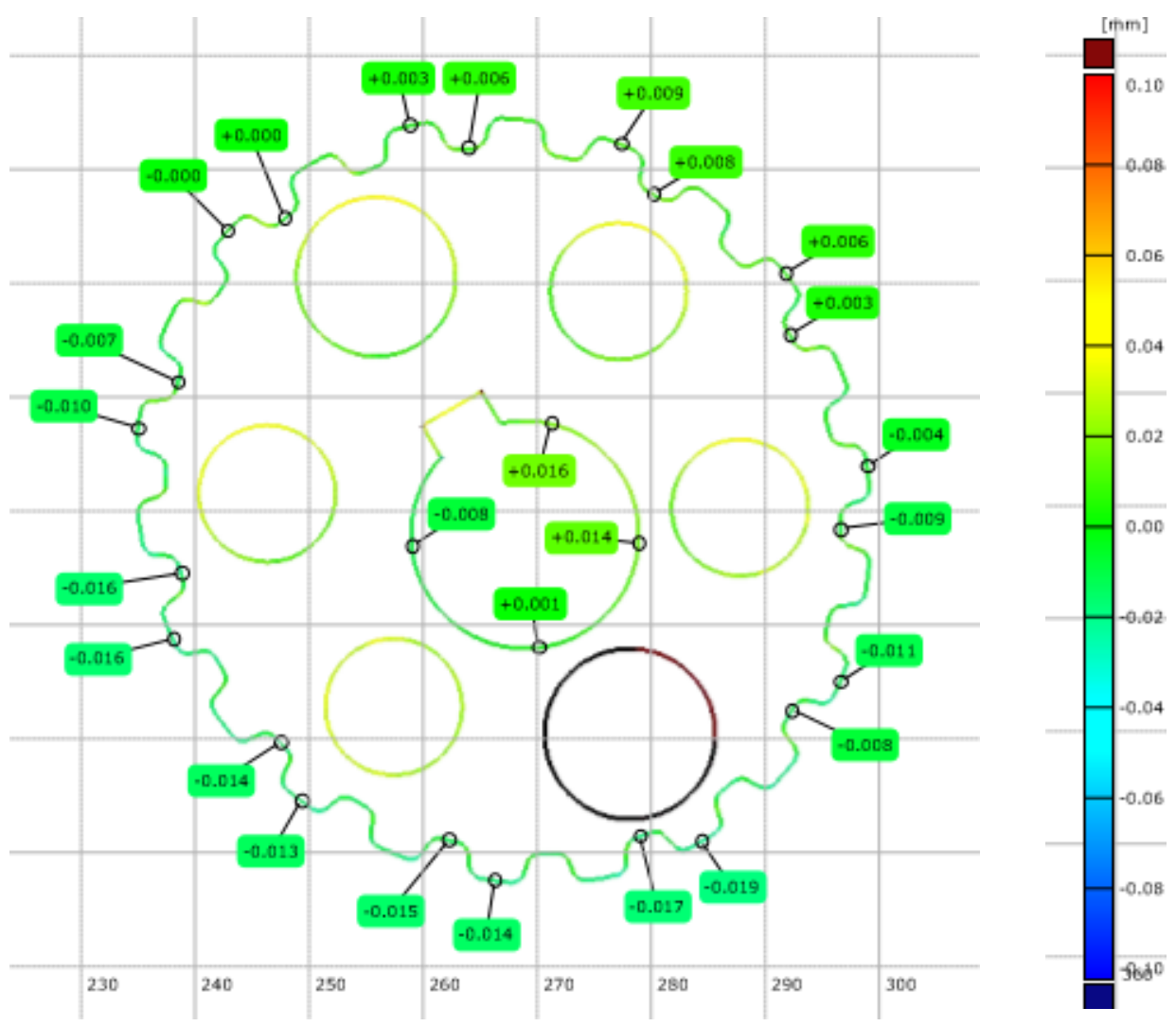

Fig. 10. The detailed values of the deflections of shape of cogbelt pulley

\section{References}

1. K. Oczoś, Cena I. Rapid Inspecton - metody pomiarowo-kontrolne adekwatne do rapid technologii. Mechanik 3, 165-178 (2008)

2. S. Medvecká-Beňová, Meshing Condition and Kinematic Properties of non-circular GearActa. Mechanica Slovaca 20 (2), 16-21 (2016)

3. P. Krawiec, A. Marlewski, Profile design of noncircular belt pulleys. Journal of Theoretical and Applied Mechanics 54 (2), 561-570 (2016)

4. P. Krawiec, Projektowanie i kształtowanie uzębień nieokragłych kót pasowych, Acta Mechanica et Automatica 4, 52-55 (2010)

5. M. Kujawski, P. Krawiec, Analysis of Generation Capabilities of Noncircular Cog belt Pulleys on the Example of a Gear with an Elliptical Pitch Line. Journal of Manufacturing Science and Engineering. Transactions of the ASME 133 (5), 05100610510067 (2011)

6. M. Sobolak, G. Budzik, Experimental method of tooth contact analysis (TCA) with rapid prototyping (RP) use. Rapid Prototyping Journal 14 (4), 197-201 (2008)

7. J. Butler, D. Aitchison, Using selective laser sintering for manufacturing. Rapid Prototyping Journal 31 (3), 212-219 (2011) 